LETTER

\title{
Growing of black pepper by small farmers in the city of Capitão Poço, PA, Brazil
}

\author{
Letícia do Socorro Cunha ${ }^{1 *}$, Luane Laíse Oliveira Ribeiro ${ }^{1}$, Felipe Cunha do Rego ${ }^{2}$, Francisco Lailson da \\ Silva de Oliveira ${ }^{2}$, Alysson Oliveira de Carvalho', Luã Souza de Oliveira ${ }^{2}$, Marcos Vinicius Reis de Oliveira \\ Junior $^{2}$, Jéssica da Silva Schmidt ${ }^{1}$, Fernanda Ludmyla Barbosa de Souza ${ }^{1}$, Emerson Fey ${ }^{1}$, Wanderson \\ Cunha Pereira $^{2}$ and Francisca das Chagas Bezerra de Araújo ${ }^{2}$
}

${ }^{1}$ State University of Western Paraná, Marechal Cândido Rondon, PR, Brazil ${ }^{2}$ American Rural Federal University, Captão Poço, PA, Brazil. *Author for correspondence: leticiacunhaufra2013@hotmail

\section{OPEN ACCESS}

(c) The Authors

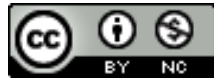

Submitted on July 13, 2019 Accepted on September 03, 2019 Early View on September 19, 2019 Final Publication on September 23, 2019

Authors declare no conflict of interest KEYWORDS:
Producers Producers Varieties

\section{ABSTRACT}

The objective of this work was to conduct a study on the cultivation of black pepper by small farmers in the city of Capitão Poço / PA. The research was developed based on the application of semi-structured questionnaires, in order to identify the form of cultivation of black pepper in the municipality carried out by family farmers, where a total of 50 producers were interviewed, and this sample was defined based on amount of small producers in the municipality. In addition, other resources were used, such as photographic records, audio recording, notes in field notebooks and direct and indirect observations, which also supported the research. Most respondents $(46 \%)$ have been producing black pepper for over ten years, and $38 \%$ have reported growing the crop between five and ten years, $54 \%$ of producers said that the cultivation practice of the crop was adhered to. income supplementation and $32 \%$ said it was a passed on activity from father to son and the main variety cultivated by farmers $(56 \%)$ is kotanadan. Thus, it was found that the main factor of cultivation of black pepper, is the complementation of income of small producers, using the variety kotanadan, because it is easily accessible in family farming of the studied region.

\section{Highlighted Conclusion}

The main factor for cultivation of black pepper var. kotanadan is the supplementation of income of familiar producers.

\section{INTRODUCTION}

Black pepper (Piper nigrum L.) is a perennial creeper species belonging to the Piperacea family, originating from tropical regions of India. After its introduction in Brazil, the crop has been highlighted by the high economic yields for small and medium producers, especially in the Amazon Region (Embrapa 2006). In Brazil, a few dozen varieties of pepper are produced. Among them, black pepper is one of the most important in the process of obtaining income by farmers, especially family members, in the North and Northeast Regions of the country (DESER 2008).

Traditionally, this crop is widely grown in Capitão Poço, gaining prominence in family farming, where it is responsible for most of the production of the state of Pará, due to its high profitability in the commercialization periods. According to IBGE (2005), Pará is responsible for almost $84 \%$ of Brazilian production, demonstrating the increase and importance of this crop to obtain farmers' income, as well as reflecting current product prices in the domestic and global markets.

For Moraes et al. (2018), family production has been modernized with the introduction of new living tutoring techniques using gliricidia and more resistant species, generally revealing positive impacts on the local economy. Thus, it is necessary to understand the possibilities of changes in production systems in order to be able to subsidize farmers in introducing certain changes in production systems. In this sense, it is essential to gather information from farmers about cultivation and consequently direct the development of future research to boost social and economic development in the municipality.

The objective of this work is to conduct a study on the cultivation of black pepper by small farmers in the city of Capitão Poço/PA. 


\section{MATERIAL AND METHODS}

The field research was carried out from December 03, 2018 to January 14, 2019, with the producers of black pepper belonging to the city of Capitão Poço / PA. In this locality the cultivation of the crop is developed by both small, medium and large producers. However, this is an agricultural activity that helps supplement the income of small farmers in the current agricultural environment in the region.

The city of Capitão Poço is located at a latitude of $01^{\circ} 44^{\prime} 47^{\prime}$ "S and a longitude of $47^{\circ} 03^{\prime} 34^{\prime \prime} \mathrm{W}$ ). It belongs to Microregion of Guamá, mesoregion of northeastern Pará and is $226 \mathrm{~km}$ from the capital Belém. , 7 to $26.9^{\circ} \mathrm{C}$ with an annual average of $26.2^{\circ} \mathrm{C}$, only $1.2^{\circ} \mathrm{C}$. And according to the Köeppen classification the Ami climate (Silva et al. 2011), with annual precipitation around $2,500 \mathrm{~mm}$ and a short dry season between September and November (monthly rainfall around $60 \mathrm{~mm}$ ), and a relative humidity between $75 \%$ and $89 \%$ in the months with the lowest and highest rainfall, respectively (Schwart 2007).

The research was developed based on the application of semi-structured questionnaires, in order to identify the form of cultivation of black pepper in the municipality carried out by family farmers, where a total of 50 producers were interviewed, and this sample was defined based on amount of small producers in the municipality.

In addition, other resources were used, such as photographic records, audio recording, notes in field notebooks and direct and indirect observations, which also supported the research.

Data were tabulated in a Microsoft Excel $2010 \AA$ and $2013 \AA$ spreadsheet, where they were manipulated to elaborate the graphs. Finally, the interpretation and analysis of the information obtained was performed.

\section{RESULTS AND DISCUSSION}

According to the survey, the majority of respondents (46\%) have been producing black pepper for over ten years, and $38 \%$ reported producing the crop between five to ten years. Taking into consideration that the city of Capitão Poço / PA has great power in the cultivation of the crop, where according to IBGE data (2017) the amount produced and the average yield in the city of Capitão Poço/PA were 2,200 tons and 4,000 kg/ha, respectively, being among the five largest producers in the state. Thus, there are demands from the export market in agriculture, and this to some extent encourages farmers to seek new alternatives for large-scale production, assisting in the cultivation growth and income supplementation of farmers in the region.

Figure 1 shows the main factors that made the farmers adhere to the practice of cultivation of black pepper in the municipality, where $54 \%$ of producers stated that this activity was adhered to complement their income. And $32 \%$ said it was a past activity from father to son.

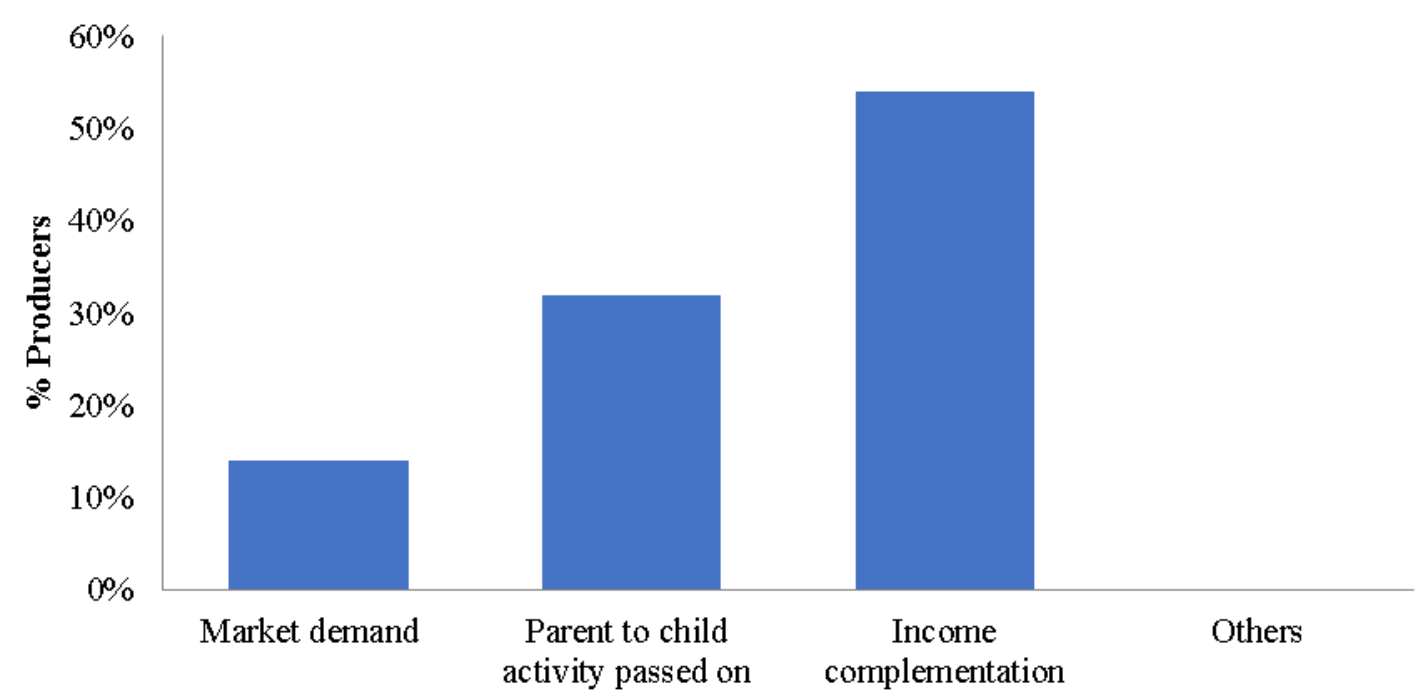

Figure 1. Main factors described by family farmers, which contributed to the adoption of black pepper cultivation in the city of Capitão Poço/PA.

In family farming, everything that comes from agriculture is used for both food and income supplementation. However, this last factor also helps in the maintenance of clothing, medicine, leisure, and in assisting food supplementation for subsistence.

When asked about the main varieties grown, $56 \%$ of farmers reported using the Kotanadan black pepper variety more (Figure 2). This can be explained due to its easy access to crop production. Other cultivated varieties were also reported by $38 \%$ of growers, including Apra pepper, India, Tira Cota, Ouro Branco and common. 
According to Rodrigues and Ataíde (2001) and Nakashima et al. (2003), these varieties grow well in soils of medium and clay texture, with depth greater than $70 \mathrm{~cm}$, with humic arable layer and good progress of subsoil structure and good drainage condition, with poor drainage being the main factor of impaired productivity, which can cause root rot diseases.

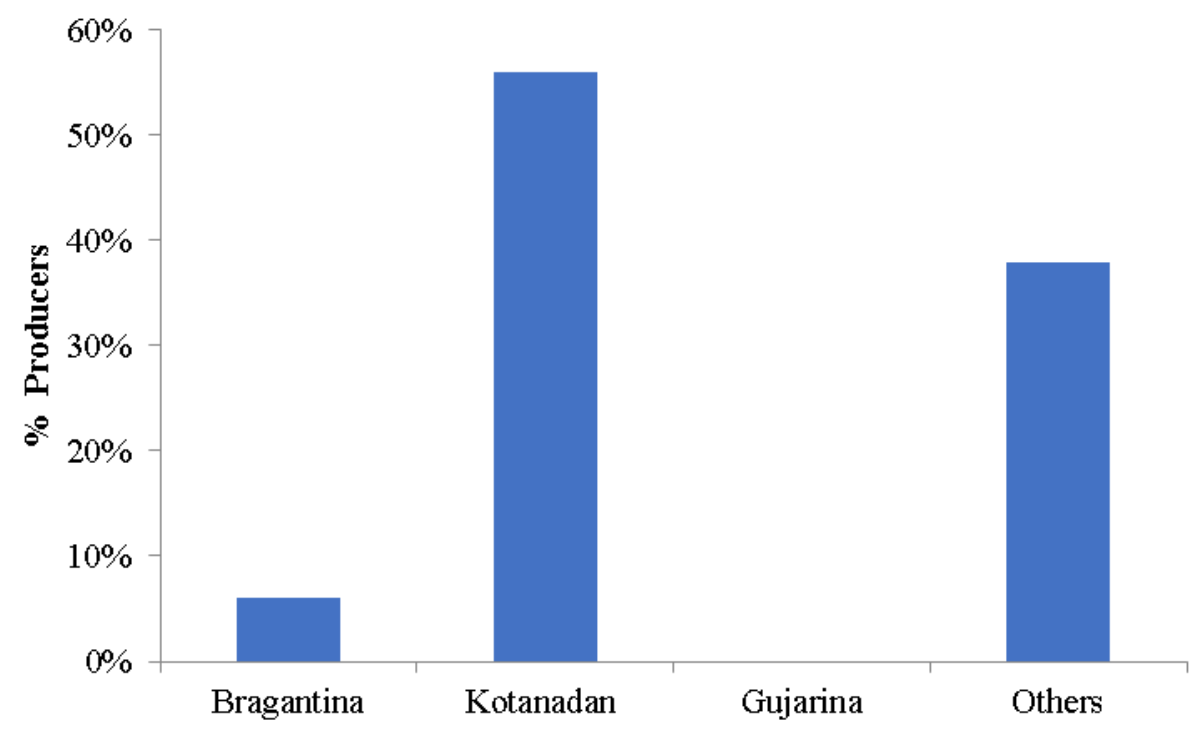

\section{Figure 2. Main varieties cultivated by small producers of black pepper in the city of} Capitão Poço/PA.

\section{Acknowledgements}

To all the authors involved in the construction of this study, for their commitment and patience in this work, and especially the small producers of black pepper, for sharing the reality lived in the field and passing on all the knowledge and information that were essential for construction. this work.

\section{References}

DESER.2008. Department of Socioeconomic Studies. Secretariat of Family Farming.

Embrapa. Brazilian Agricultural Research Corporation. The culture of black pepper. 2. ed. Brasília, DF: Embrapa Technological Information, 2006. 73p.

IBGE. 2005. Extractive Plant Production.

IBGE. Brazilian Institute of Geography and Statistics. IBGE Automatic Recovery System (SIDRA). 2017.

Moraes AJG et al.2018. Evaluation of the economic, social and environmental impacts of the cultivation of black pepper with live gliricidia tutor in the state of Pará. Brazilian Journal of Development 4: 3696-3715.

Nakashima S et al. 2003. Land Survey in Pimentais in the Immigration Region of Tomé-Açu. Belém-Pará, 2003.

Rodrigues W and Ataíde IT. 2001. Agroforestry system: "Agriculture in floors". Bethlehem: POEMAR \Amazon Scholarship. 2001.

Schwart G. 2007. Sustainable management of secondary forests: potential species in northeastern Pará, Brazil. Amazon: Science and Development 3: 125-147.

Silva AG et al. 2011. Infestation of Black Citrus Fly In Citrus Orchards In Conventional And Agroforestry Planting Systems. Brazilian Journal of Fruit Farming 33: 053-060. 